discharged on Dec. 12th ; stay after operation twenty-five days. The patient's illness dated from three weeks previous to adnission. Diagnosis: pyo-pneumothorax (?). Nov. 17th: Three-quarters of an inch of the eighth rib excised, and eleven ounces of extremely fetid pus evacuated. Pleura treated in exactly the same way as before.-18th: Very little watery discharge; not offensive.-20th: 'Tube shortened on the fourth day.-24th: 'Tube left out on the eighth day,-30th: Wound healed on the fourteenth dav. The temperature throughout was normal. Weight on almission, $49 \mathrm{lb}$; on discharge, $54 \mathrm{lb}$.

CASE 4. (Also under the care of Dr. Turner.)-Lliz. W-aged two years and a half. Admitted on Nov. 19th; died on Dec. 15th. Ill six weeks before admission.Nov. 20th. Portion of the eighth rib on the left silge resected, and three ounces of pus evacuated. Operation the same as before. Temperature for next three days normal.-22nd: Tube shortened.--23rd: Temperature has reached $1026^{\circ},-28$ th: The temperature has been down since last note. Tube left out on the ninth day.-Dec. lst: Temperature still normal. Wound healed on the twelfth day.-2nd: Temperature rose suddenly to $102 \cdot 8^{\prime \prime}$. Wellmarked signs of broncho-pneumonia in left lung. The child gradually sank and died.

CASE 5. (Under the care of Dr. Pasteur.)-Mary A. 1) aged a year and nine months. Admitted on Nov. 28th ; in hospital at the present time. -Nov. 29 th. Rib resected, and six ounces of pus let out; details as before; pus very fetid. 30th. Watery and almost odourless discharge. 'The temperature came down to normal and remained so.-Dec. 6th. The tube was shortened on the third and eightl days. - 8 th. Tule left out on the tenth day. - 12th. Wound healed on the fourteenth day. The child is gaining weight slowly.

CASE 6. (Also under the care of Dr. Pasteur.)-A. B aged five years and eleven months. Admitted on Nov. 20th; discharged on Dec. 2lst; stay in hospital twenty-nine days. - Nov. 22nd: Portion of seventh rib resected, and nine ounces of pus evacuated ; details the same. The temperature came down to normal after operation and remained so till the $30 \mathrm{th}$, when for a week it fluctuated between $98^{\circ}$ and $103^{\circ}$, and then returned to normal ; this rise was thought to be due to iodoform.--26th: Tube shortened on the eighth day.-30th : Tube left out on the ninth day.Dee. 3rd: Wound healed on the twelfth day.

Remarks by Mr. BLAKE. - For permission to publish these cases I am indebted to the kindness of the medical staff of the above hospital. These are the last six empyemata that have been treated in the hospital, and are not selected cases. All were treated in precisely the same manner-viz., a portion of rib was excised, the fluid pus allowed to run out, the flaky semi-organised lymph removed with a sharp spoon, and finally four ounces of iodoform emulsion injected into the pleural cavity, three ounces of which were allowed to run out. That the iodoform emulsion materially hastened the healing process there can be little doubt, for in all cases except one the drainage tube was left out on the ninth day (on the twelfth in the exceptional case), the wound healing -that is, the communication between the pleural cavity and the external air being shut off-from the twelfth to the sixteenth day.

\section{RUGBY HOSPITAL.}

A COMPLICATED AND FATAL CASE OF PERNICIOUS ANEMIA; NECROPSY; REMARKS.

(Under the care of Dr. (Lement Dukes.)

We reviewed the more recent literature and treatment of pernicious anæmia in our editorial remarks (see page 75) on a case which was cured by the administration of arsenic This in an example of the disease in which that drug did not prove a specitic, although carefully administered. It is not unusual to find effusions of fluid in the serous cavities, and the absence of any coarse naked-eye lesion is characteristic of the disease. There are few maladies which present so much difficulty in diagnosis, and the physician, knowing the fact that an appearance similar to that of pernicious ansmia is occasionally found in association with malignant disease, changes in the gastric mucous membrane, the presence of intestinal worms, \&c., is usually very cautious in expressing an opinion as to the nature of the case in which some of these may be present, though concealed.

T. B-, aged thirty-one, was admitted on Dec. 10th, 1888. He appeared seriously ill, and was said to have been ailing for the last three years. He and his family had been in an almost destitute condition owing to his feebleness in health, which prevented lim from working sufficiently to support them. He had been at work until five wceks previously. Ile was sent into the hospital with a history of having been laid up with rhemnatic fever during five weeks. This may have been so, but there was no evidence of it on admission beyond some amount of aching all down the left side, which pained him when he moved in bed. There were no physical signs detected of any disease in his circulatory or respiratory systems, but he was exceedingly pale and white in his complexion. Pulse 120 and regular; temperature $101^{\circ}$; tongue dry and brown; bowels constipated; urine free from albumen

On Dec. 12th Dr. Dukes failed to discover any further physical signs. Mentally the man was very dull, heavy, and torpid liy day ; while at night he was restless, sleepless, and wandered when between sleeping and waking. He was evidently very ill. Arsenic every three hours was prescribed on account of his great pallor. On Dec. 15th well-marked recent pleurisy on both sides of the chest was detected, but there was no cough. His abdomen was full, firm, and doughy. Dr. Dukes thought that it was going to prove a case of acute general tuberculosis. On the 17 th the patient passed by the bowels a large steel screw; the length of it was an inch and three-quarters, and the diameter of the head three-eighths of an inch. He had no knowledge as to how it found its way into his intestines. His tongue was coated with a hard, dry, brown fur. The temperature averaged $101^{\circ}$ and the pulse 120. There was a low muttering delirium and a general muscular twitching all over his body, which became more prevalent during sleep. The urine was quite free from albumen. He had had no rigor. On most days he had vomited once. He was still constipated. He took his liquid nourishment well. The question arose as to whether this large screw could have in any way injured him so as to set up septicæmia. On Dec. 18th the pleurisy had become more diffused, and there was a loud mitral systolic murmur, audible chiefly at the apex. He was much worse. The pulse was fluttering, and the muscular twitching much more manifest. It now seemed as though infecting endocarditis was commencing, and causing septicæmia; the pallor also was increasing. Quinine was prescribed and the arsenic was increased. On the 20th there was still the mitral murmur, and the heart seemed all " bruit," there being no sounds over any of the valves that were not accompanied by loud murmurs. The pulse was very feeble, about 120 ; the temperature varied from $99 \cdot 4^{\circ}$ to $101^{\circ}$ The tongue was cleaner, but very pale. The muscular twitching was subsiding. He was gradually becoming more of a jaundice-yellow, but the sclerotics continued white and clear. On Jan. 1st, 1889, there was considerable epistaxis. After this date he gradually became weaker and more prostrate; his colour assumed the characteristic lemon-yellow hue of pernicious anæmia, and on Jan. 1lth, he died exhausted, notwithstanding his gradually increasing doses of arsenic.

Dr. Dukes made a post-mortem examination, and found all the organs apparently healthy, though they were mostly white and flabby. The spleen was, perhaps, slightly enlarged, though healthy in appearance. The liver and kidneys were pale. The heart was large, white, and soft; the valves all healthy and competent. There was an excess of pericardial fluid. On the right side of the thorax the lung was adherent to the thorax throughout by recent adhesions; on the left there was considerable pleuritic fluid, without adhesions. The blood was every where fluid, not a particle of clot except a few fine shreds interlaced in the chorda tendineæ. It was not only fluid, but a very dirty, waterylooking red, and very little resembled blood. It was evidently of a disintegrated nature.

Remarks by Dr. DUKEs. - It seems to me that these cadaveric poisons generated in the intestinal tract, and de scribed by Dr. Wm. Hunter, which are probably ptomaines, when generated slowly or in small quantity, are so capable of gradually disintegrating the blood as to give rise to the symuptoms of pernicious anæmia; while when they are generated rapidly, or in large quantity, they so quickly destroy the blood as to cause purpura hæmorrhagica.

MEDICAL WOMEN IN Russia.-It is announced in the daily press that the Russian Government has found it necessary to issue a regulation forbidding female medical practitioners to attend adults of the male sex. What has led to this order has not as yet transpired, but it is not improbable that some case of scandal may have occurred. 